Article

\title{
Investment and Profitability of Community Heating Systems Using Bioenergy in Finland: Opportunities and Challenges
}

\author{
Raghu KC *(D), Jarno Föhr (D), Arun Gyawali and Tapio Ranta $(D)$ \\ Laboratory of Bioenergy, Lappeenranta-Lahti University of technology LUT, Lönnrotinkatu 7, \\ 50100 Mikkeli, Finland; jarno.fohr@lut.fi (J.F.); arun.gyawali@lut.fi (A.G.); tapio.ranta@lut.fi (T.R.) \\ * Correspondence: Raghu.kc@lut.fi; Tel.: +35-8440668434
}

Citation: KC, R.; Föhr, J.; Gyawali,

A.; Ranta, T. Investment and

Profitability of Community Heating

Systems Using Bioenergy in Finland:

Opportunities and Challenges.

Sustainability 2021, 13, 11757. https:/ /

doi.org/10.3390/su132111757

Academic Editor: Alberto-Jesus

Perea-Moreno

Received: 23 August 2021

Accepted: 18 October 2021

Published: 25 October 2021

Publisher's Note: MDPI stays neutral with regard to jurisdictional claims in published maps and institutional affiliations.

Copyright: (c) 2021 by the authors. Licensee MDPI, Basel, Switzerland. This article is an open access article distributed under the terms and conditions of the Creative Commons Attribution (CC BY) license (https:// creativecommons.org/licenses/by/ $4.0 /)$.

\begin{abstract}
Oil heating systems are abundant in rural Finland and they need to be replaced by renewable energy as Finland aims to be carbon neutral by 2035. Bioenergy, one of the renewable energies, is a common source of energy in Finland as the country is rich in forest resources. In Finland, combined heat and power plants utilize such resource to produce district heat and electricity but Finnish rural areas do not have access to the district heating network. However, there are potential scenarios where community heating could be possible using portable chip-fired heating systems (heat containers). Ultimately, the cost of heating is an important factor for the consumers and the cost of investment is likely to put off any interest from the communities. In this research, we explored the cost and profitability of heat container investments in rural Finland and examined the challenges for the energy transition away from oil heating systems, as well as the opportunities decentralized biomass-fired heating systems might bring. The results of this research indicate that the price of heat produced in heat containers is comparatively higher than district heating, which is commonly used in cities in Finland, but is cost-competitive compared to oil heating depending on the price of oil. For example, the current price of LFO ( 1 EUR/l) generates costlier heat than the $300 \mathrm{~kW}$ heat container provides. Firing wood pellets in the heat container is not economically viable due to expensive raw material but smaller-sized heat container $(110 \mathrm{~kW})$ firing wood chips could provide cost-competitive heat if uptime is raised to $>2700 \mathrm{~h} /$ year. There are socio-economic impacts and value-added effects on the rural region due to utilization of local resource instead of imported LFO but there remain challenges and barriers such as high initial investment, low investment support and lack of policies focused on decentralised energy enterprises.
\end{abstract}

Keywords: heating; biomass; bioenergy; cost; profitability; economy

\section{Introduction}

\subsection{Background}

According to the intergovernmental panel on climate change, global temperatures above $1.5{ }^{\circ} \mathrm{C}$ compared to pre-industrial levels will accelerate the mass extinction of species, and more areas of the world will become unhabitable, risking reduced food production, loss of access to water resources and permanent damage to the ecosystem [1]. Many developed countries are cutting down their carbon emissions to fight the imminent threat of climate change. In Europe, countries are collectively and individually setting their own goals as part of the Paris Agreement on climate change, including Finland which aims to be carbon neutral by 2035 [2].

Renewable and low carbon energies such as bioenergy are a cornerstone of many countries' energy strategy which provides a key to decarbonization of their energy sector. Due to its potential, availability and fuel flexibility, bioenergy plays a key role in Finnish economic development [3]. In Finland, wood fuels covered 380 PJ of energy consumed in 2019 , which is $27.9 \%$ of the total energy consumed (1362 PJ) [4]. On the other hand, space heating required about $283 \mathrm{PJ}$ and district heating contributed $123 \mathrm{PJ}$ from which 
residential use was about $54 \%$ of it [5]. These figures suggest that bioenergy in the energy mix is crucial in the future, especially in the space heating sector. Furthermore, as coal will be phased out from the energy sector in 2029 [6] and decreasing number of papermills may boost biomass availability, utilisation of biomass as a low-carbon energy solution in the future [7].

The statistics centre of Finland defines heating systems as "the main method of heating used in the heating of a building" and categorizes them as: central heating (water), central heating (air), direct electric heating, stove heating, no fixed heating installation, and unknown. Among these, stove heating includes stoves that use wood or oil as a fuel, whereas central heating (district heating) refers to the processed heat from industries such as combined heat and power [8]. In most Finnish cities, a system of shared district heating is provided. This typically involves piping warm water produced in combined heat and power plants to homes in the city which is impractical for rural regions. According to the statistics on Finland from 2019, 43.37 TWh of energy was used for household spatial heating. Out of this, 5.4\% was generated by light fuel oil [LFO] and the majority was consumed in detached houses [9]. According to the research from 2016, in Finland, there are still about 200,000 oil heating systems which consume about 460 million liters of oil annually. With a $2.64 \mathrm{~kg} \mathrm{CO}_{2 \mathrm{eq}} / 1$ emission factor, the total annual carbon emissions are about 1.21 million metric tonnes of $\mathrm{CO}_{2 \mathrm{eq}}$ from residential heating due to burning fossil fuels [10], and these heating systems need to be eliminated to achieve the carbon neutrality.

\subsection{Portable Heat Containers as a Solution}

A heat container is a complete integrated boiler-storage package constructed according to the EN303-5 standard for heat production ranging from 60-500 kW [11,12]. A schematic diagram of a heat container is illustrated in Figure 1. In the system, wood chips are fed through a conveyer from section A to section B where the boiler is situated. Portable heat containers offer a solution to those who are looking for a renewable alternative in rural areas where the extension of the district heating network is unrealistic.

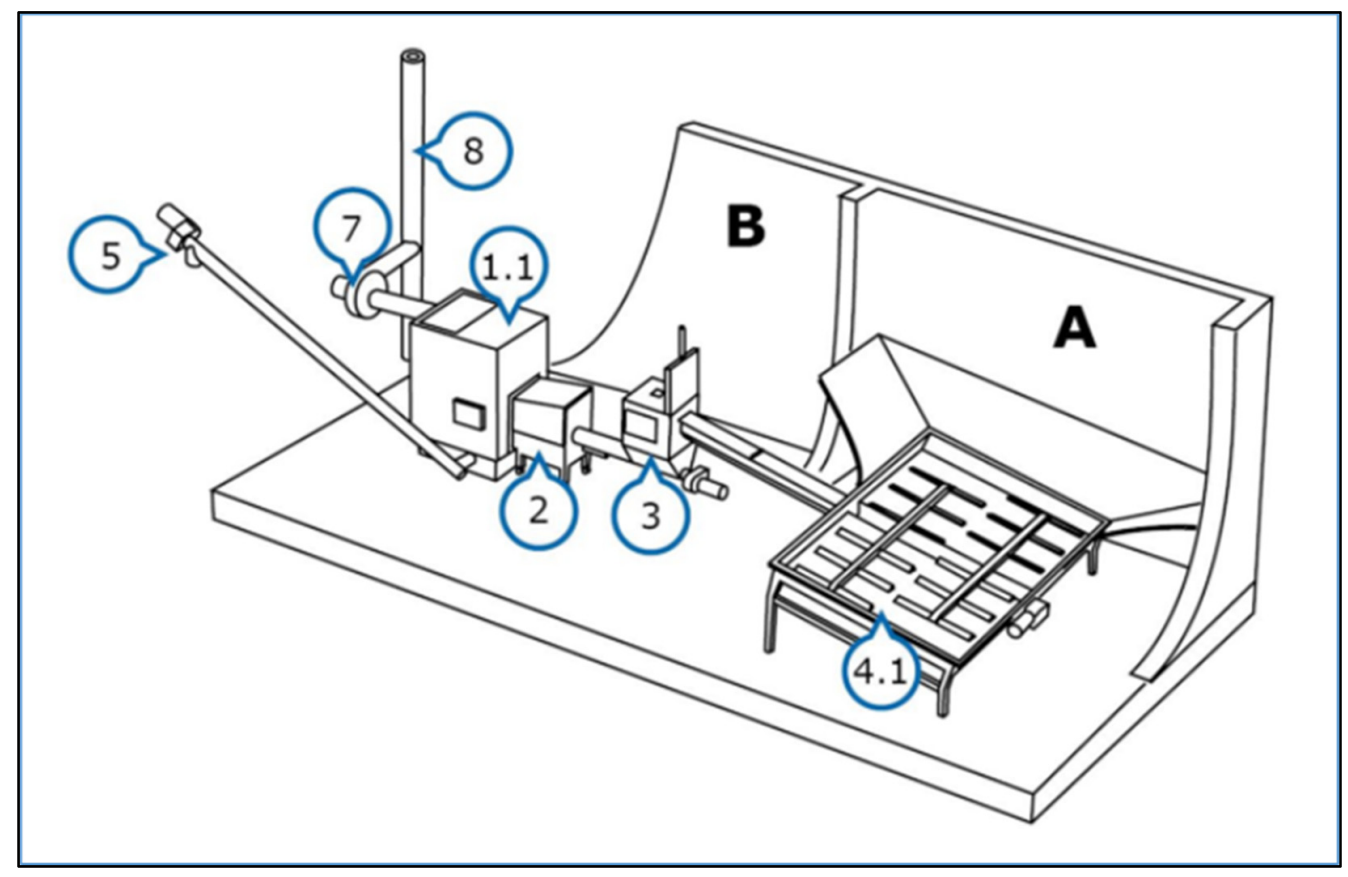

Figure 1. A schematic diagram of a heat container which has two compartments, a fuel storage (A) and a boiler room (B). Components include a boiler (1.1), burner (2), temporary storage (3), bottom unloader (4.1), ash remover (5), flue gas remover vacuum (7) and a chimney (8) [12]. 
The new heat containers are suitable for the heating of small communities, large-sized industrial buildings, as well as larger-sized family houses [13]. Portable heat containers can be installed in a few hours after the necessary base construction of a concrete slab in addition to the installation of heat transfer channels, water pipes and electricity. Similarly, the heat container can also be technically set up simply on gravel peds or portable concrete beams [12,13]. This is one of the cost advantages of heat containers. The chip storage that is integrated into the heat container eliminates the need for additional space as well as investment for a separate fuel storage facility. Heat containers are often the products operated by local small-size energy enterprises. In Finland, heating plants owned by energy enterprises have been growing constantly from 330 in 2006 to 608 in 2015. Most of these enterprises focus on local forest resources (30-50 $\mathrm{km}$ of radius) [14].

However, there are environmental concerns regarding the installation of biomass-firing power plants in the residential areas due to the flue gas that contains NOx, particulate matter, and in some cases unburnt particulate emissions which could be some of the limitations to the use of small-sized boilers in residential areas. In addition, the consequent odour could be unsuitable in residential areas [15]. In contrast, Young et al., report in their case study that the air quality due to the biomass combustion has negligible effects in the context of implementing decentralized biomass derived heating systems [16]. There is a lack of prior research on cost competitiveness and other practicalities of small-scale biomass firing for community heating even though biomass provides price stability of delivered heat to some extent [17].

Energy transition from relatively reliable LFO-derived heating systems to renewable energy-derived heating systems is a societal challenge which requires a radical shift in sociotechnical systems [18]. According to Hess and Sovacool [18], the transformation of a sociotechnical system brings together heterogeneous mix of people, norms and laws, cultural categories, research, infrastructures and natural resources. Peltola [19] believes that such transformation is not solely about technological transformation but also involves sociocultural and economical processes. According to Komendantova [20], public participation is a key for bringing trust and credibility to the energy transition. Komendantova also found in their multi-criteria decision analysis on energy transition that economic concerns were the highest priority for the stakeholders from Austria, Germany, Finland, Morocco, Jordan and Iran. Furthermore, the stakeholders were concerned whether the change would be costly for them and whether the change would bring sufficient economic stimulus for the job market. In addition to the costs, securing a domestic source of energy was one of the top priorities for the stakeholders [20].

The primary aim of this paper is to assess economics of the energy transition from imported LFO-derived heating system to renewable energy-based heat produced with wood chips, and to examine the important factors that have effects on the price of the delivered heat. Specifically, this paper will compare the break-even price of heat produced from small-scale LFO-fired heating system (considered as business-as-usual, BAU) with heat produced in wood chips-fired heat containers. LFO-derived heating system is chosen as a BAU scenario because they are popular among the rural communities and need to be phased out with renewable source of energy in order to achieve carbon neutrality. The results will also be compared with heat from pellet-fired heat containers. The secondary aim is to discuss the economic opportunities small-scale biomass derived heat offers and the potential barriers for the implementation in rural communities of Finland in the discussion section.

\section{Materials and Methods}

\subsection{Background}

The underlying premise of this study is that housing associations need to change their heating systems. Some alternatives are illustrated as scenarios below. It is assumed that entrepreneurs in the heating industry would invest in heat containers and install them in 
the vicinity of the users and provide maintenance as well as handle the chip delivery and finally invoice the users.

For the BAU scenario, it is assumed that a housing association would invest in a new oil heating system. It would maintain and take care of the fuel storage and delivery, and the association would also handle the invoicing.

Differently sized heat containers powered by different fuels are compared in Table 1. The nominal powers of the heat containers are $110 \mathrm{~kW}$ and $300 \mathrm{~kW}$ and the efficiency of biomass heat containers is assumed to be $91 \%$, while the counterpart efficiency for oil heaters is assumed to be $95 \%$. The yearly uptime is assumed to be $2000 \mathrm{~h}$. The price of oil is taken from the statistics for Finland as the average price for consumers and value added tax (VAT) has been removed for consistency. The state support for investments in renewable energy is typically $20 \%$ in Finland.

Table 1. Basic information about the heating system and capital costs.

\begin{tabular}{ccccccc}
\hline Categories & Unit & \multicolumn{2}{c}{ Chips } & \multicolumn{2}{c}{ Pellets } & BAU \\
\hline Nominal power & $\mathrm{kW}$ & 110 & 300 & 110 & 300 & 300 \\
\hline Efficiency & $\%$ & 91 & 91 & 91 & 91 & 95 \\
\hline Uptime & $\mathrm{h} /$ year & 2000 & 2000 & 2000 & 2000 & 2000 \\
\hline Heat demand & $\mathrm{MWh} / \mathrm{a}$ & 220 & 600 & 220 & 600 & 600 \\
\hline Fuel price & $€ / \mathrm{GJ}$ & $6.12^{1}$ & 6.02 & $13.17^{2}$ & $13.17^{2}$ & $19.08^{3}$ \\
\hline Annual Own energy cost & $€$ & 264 & 724 & 264 & 724 & \\
\hline Capital investment & & & & & & \\
\hline Base construction & $€$ & 7000 & 7000 & 7000 & 7000 & 1000 \\
\hline Equipment cost & $€$ & 100,000 & 200,000 & 100,000 & 200,000 & 15,000 \\
\hline Other administrative costs & $€$ & 1000 & 8000 & 1000 & 8000 & 1000 \\
\hline Support & $\%$ & 20 & 20 & 20 & 20 & 0 \\
\hline
\end{tabular}

${ }^{1}$ Calculated based on raw materials from Savonlinna using Equation $(1) .{ }^{2}[21]{ }^{3}$ Based on the price of LFO $0.81 € / 1$ (before $24 \%$ VAT) [22], $12.22 \mathrm{kWh} / \mathrm{kg} \mathrm{HHV}$, and $0.96 \mathrm{~kg} / 1$ density [23]. ${ }^{4} 1 \%$ of the heat demand and $120 € / \mathrm{MWh}$ electricity price [24]. ${ }^{5}$ The capital investment cost is referenced to [24]. According to the source [24], the administrative costs for $300 \mathrm{~kW}$ heat container is significantly higher than for $110 \mathrm{~kW}$ heat container due to significantly higher specifications in permit acquisition.

\subsection{Fuel}

It was assumed that the heating value of the chips is $2.22 \mathrm{kWh} / \mathrm{kg}$ at $45 \%$ moisture [25]. The price of the wood chips is calculated from the individual stumpage price of $4.64 \mathrm{EUR} / \mathrm{m}^{3}$ and was taken from the national statistics [26]. Based on [27], the logging price was $19.1 \mathrm{EUR} / \mathrm{m}^{3}$, the cost of forwarding and piling are 5.6 and $0.5 \mathrm{EUR} / \mathrm{m}^{3}$, respectively and the cost of unloading and chipping at the terminal is $2.4 \mathrm{EUR} / \mathrm{m}^{3}$ and $4.8 \mathrm{EUR} / \mathrm{m}^{3}$, respectively. The driver's fee is calculated from the driving time $(2 \mathrm{~h})$, the driver's cost per hour (70 EUR) and the additional cost of waiting during loading and unloading $(1.45 \mathrm{~h})$ [28]. The fuel cost is calculated from the distance of the drive and the fuel consumption for a $9 \mathrm{t}$ truck. For a sensitivity analysis, different distances and chipping methods are assessed.

Thus, the chip price is then calculated using Equation (1):

Chip price

$$
(c p)=s+1+f+p+c t+d+f c
$$

where,

$\mathrm{s}$ is the stumpage price,

1 is the logging price,

$\mathrm{f}$ is the forwarding price, 
$\mathrm{p}$ is the piling price,

ct is chipping at the terminal,

$\mathrm{d}$ is the driver's salary, and

fc is the fuel cost.

The pellet price was referenced to the going consumer price for pellets [21].

\subsection{Cost Calculation}

The assumption is that the local authorities will provide support amounting to $20 \%$ of the investment. The discount rate was assumed to be $5 \%$. The interest rate was taken to be $2 \%$ and a loan would be taken for a duration of 240 months, which is also the lifetime of the heating system and has no residual value after that period.

The annuity is calculated using Equation (2) [29]:

$$
a=\frac{\mathrm{I} \times \mathrm{i}(1+\mathrm{i})^{t}}{(1+\mathrm{i})^{t}-1}
$$

where,

I is investment costs

$i$ is interest rate

$t$ is lifetime in years (20)

The net present value (NPV) is calculated using Equation (3) adjusted from [30]:

$$
N P V=\sum_{t=1}^{n} \frac{C_{t}}{(1+k)^{t}}-I_{0}
$$

where:

$C_{t}$ is the net cash flow at the end of year $\mathrm{t}$,

$I_{0}$ is the initial investment,

$k$ is the discount rate, and

$t$ is the lifetime in years (20).

\subsection{Sensitivity Analysis}

A sensitivity analysis was carried out for the assessment of the minimum price of the heat for the NPV using different variables such as the interest rate, amount of heat sold, governmental support for investment, and price of the heat container. The reason for conducting a sensitivity analysis on operating time is to assess how much impact selling more heat (to a higher number of customers) would have on the breakeven price of the heat. Similarly, reason for assessing the impact of price of heat container on the delivered heat is because the heat-container technology is still in young and its price may go down depending on technological developments in the future. In addition, due to the Finnish climate conditions, the heat demand may vary year to year.

\subsection{The Origin of the Chips and Chipping Method}

In the baseline calculation the price of the chips was assumed to be $22.03 \mathrm{EUR} / \mathrm{MWh}$, which was calculated using Equation (1) with the chips assumed to originate from roughly $100 \mathrm{~km}$ away and chipped at a terminal $10 \mathrm{~km}$ away from the use location. However, in the sensitivity scenario differently chipped chips from different locations are considered. The city of Mikkeli was selected as the use location and a biomass terminal is located at $10 \mathrm{~km}$ from the use location. The study also examined the effect of the price of chips that originated from different municipalities. Hirvensalmi is located at $35 \mathrm{~km}$ from the biomass terminal as well as use location. Similarly, Juva and Savonlinna are located at $44 \mathrm{~km}$ and $106 \mathrm{~km}$, respectively. These locations were selected because they are adjacent municipalities with varying distances and with biomass potential and the reason for this scenario is to 
assess the impact of biomass origin and chipping method. The locations are depicted in Figure 2. In some cases, the wood chips are chipped at the roadside by a mobile chipper. In these cases, a $9 \mathrm{t}$ chip truck that can transfer the chips directly to the heat container at the customer site is used in the scenarios. These sorts of trucks are container-based trucks that can pneumatically blow the chips into the targeted area through a pipe and are referred to as blowing chip trucks [13]. In the case of terminal chipping, a $60 \mathrm{t}$ log-truck takes stems to the terminal and a stationary chipper chips them into the $9 \mathrm{t}$ blowing chip truck.

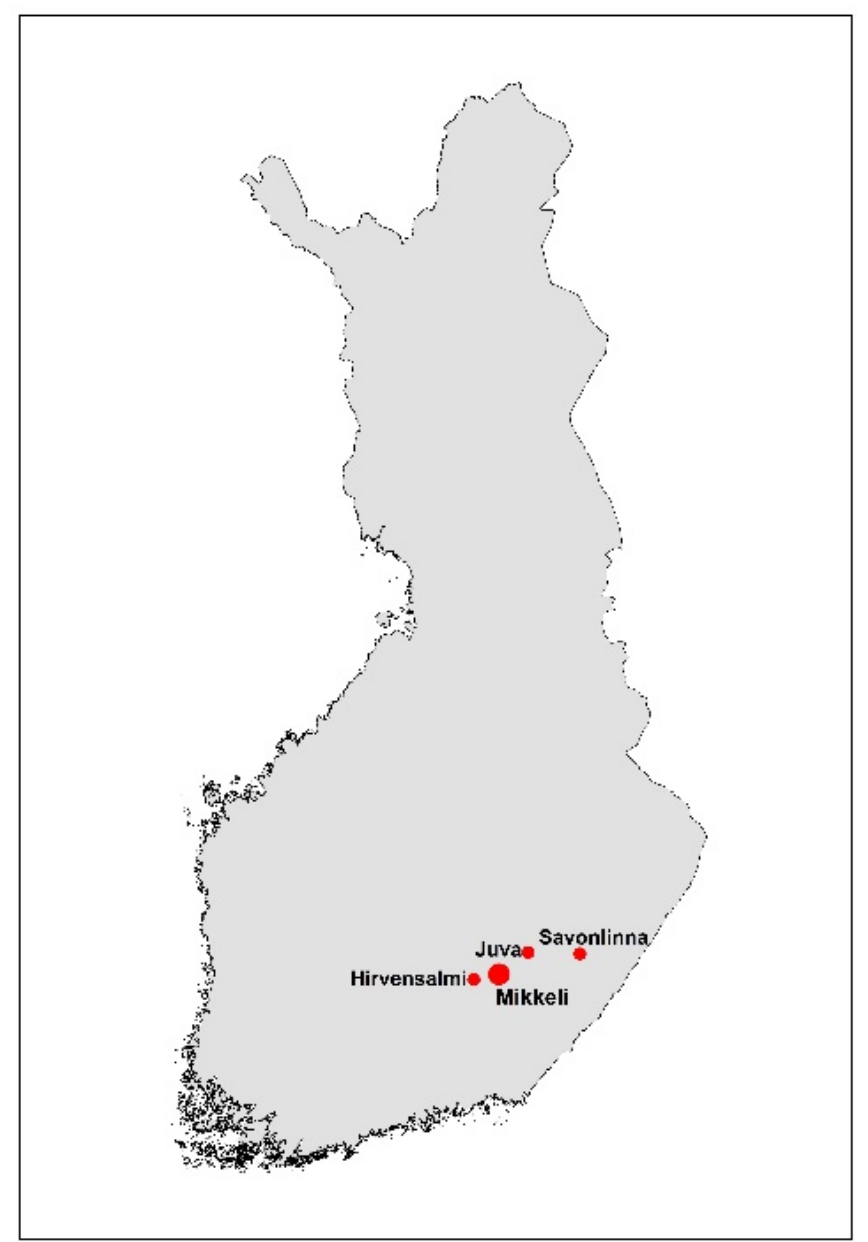

Figure 2. Map of Finland with biomass use and supply locations.

\section{Results}

In this research, all the prices are depicted as the before-tax amount unless otherwise mentioned. The results show that to achieve a positive NPV, the minimum price of heat should be $78.66 \mathrm{EUR} / \mathrm{MWh}$ in the case of the $300 \mathrm{~kW}$ heat container. The corresponding value is $96.55 \mathrm{EUR} / \mathrm{MWh}$ when the heat container is smaller in size $(110 \mathrm{~kW})$. On the other hand, corresponding values are 104.86 EUR/MWh and 122.45 EUR/MWh when using pellets as a fuel. Finally, an investment in a new oil-heating system including storage would cost a minimum of 79.8 EUR/MWh to be a profitable investment. Figure 3 presents the results for all the scenarios studied.

\subsection{Sensitivity Analysis}

\subsubsection{Housing Association Point of View}

For the sensitivity analysis, we adjusted multiple variables which have a direct impact on the price of the heat available to the consumers. One of the main analyses was to observe from the housing association's point of view. In the main study, a heating entrepreneur sold the heat to the consumers, but in this sensitivity test we assumed that the housing 
association would purchase the heat container and purchase the daily operating services from a third party and would invoice individual homes. In the assumption, the additional cost for daily operations was $4000 \mathrm{EUR} /$ year more in case of housing association [24]. The results show that the minimum price of heat would be $83.65 \mathrm{EUR} / \mathrm{MWh}$, which is $6 \%$ higher than when the heating entrepreneur invested in the operation and managed things. Results show that the housing association outsourcing the entire heating system is more sensible because most of the daily operation is outsourced to multiple contractors and is costlier than for the heat entrepreneur.

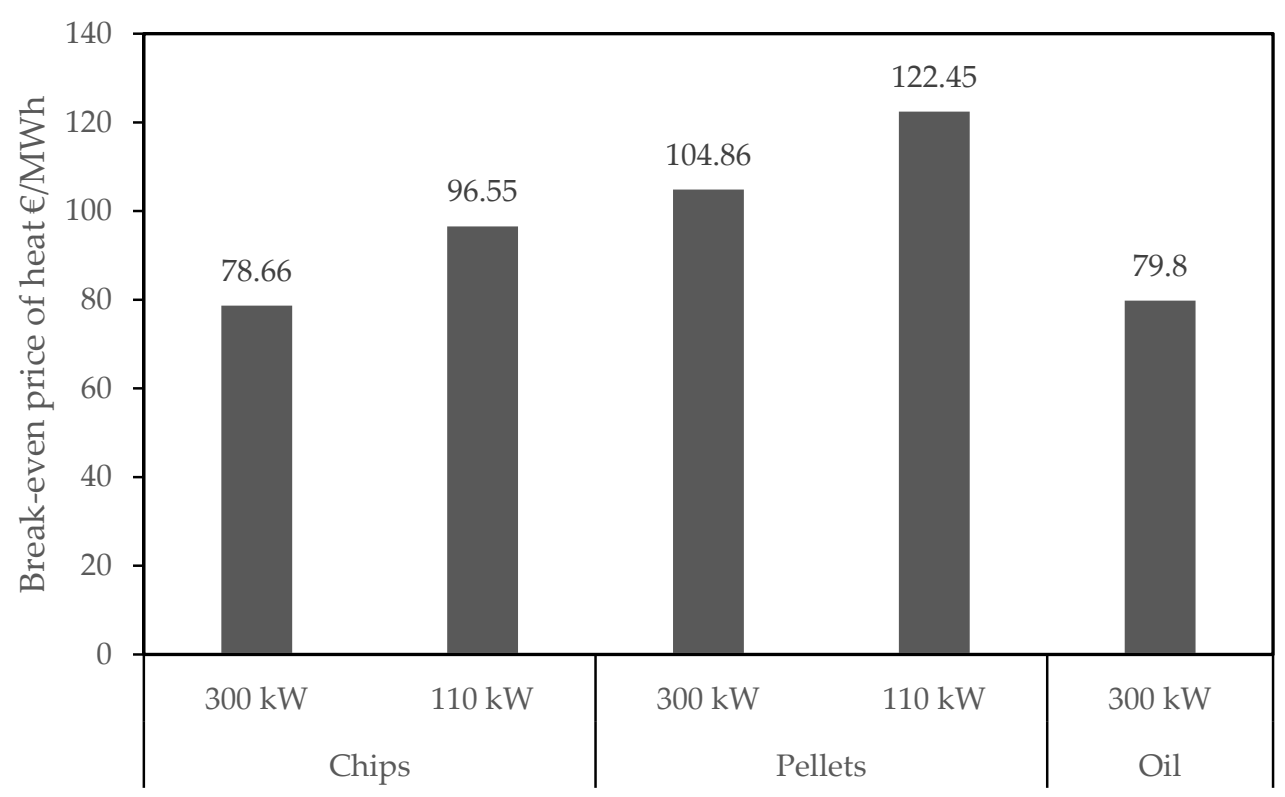

Figure 3. Break-even price of heat in different scenarios.

\subsubsection{Different Variables}

Figure 4 shows the break-even prices of heat per MWh for different scenarios in the case of $300 \mathrm{~kW}$ heat container. Figure 4 A shows that raising the interest rate to $5 \%$ would increase the price of heat to 82.41 EUR/MWh compared to 78.66 EUR/MWh with the baseline interest rate at 2\%. Furthermore, a 20,000 EUR cheaper heat container would mean that the minimum price of heat for a positive NPV comes down by 3.3 EUR/MWh compared to the baseline scenario. Similarly, a 10\% higher subsidy for renewable energy investments would result in a $4.3 \mathrm{EUR} / \mathrm{MWh}$ lower price for the heat. Finally, increasing operating time by $333 \mathrm{~h}$ would bring the break-even price of heat to $71.32 \mathrm{EUR} / \mathrm{MWh}$.

Figure 5 shows the effect of different variables on the break-even price of heat sold to the consumers from a $110 \mathrm{~kW}$ heat container. The price of the heat from pellets is expensive in all scenarios because the investment and other capital costs are the same for chips except that the operating costs (such as price of fuel) are double compared to the chips. Figure 5A shows that raising the interest rate from $2 \%$ to $5 \%$ would increase the price of heat by only $5 \%$. In contrast, reducing the price of the heat container by $25 \%$ would decrease the price of heat by $10 \%$. On the other hand, selling more heat such as from $220 \mathrm{MWh} / \mathrm{a}$ (in baseline) to $500 \mathrm{MWh} / \mathrm{a}$ would decrease the break-even price of the heat by $44 \%$. Similarly, raising $10 \%$ more in subsidies would slash the price of heat by $6 \%$ for a breakeven profitability of the investment.

\subsubsection{The Price of Chips and Its Impact}

The price of chips that originated in different municipalities for the sensitivity analysis were calculated based on Equation (1) and results for this are illustrated in Table 2. 


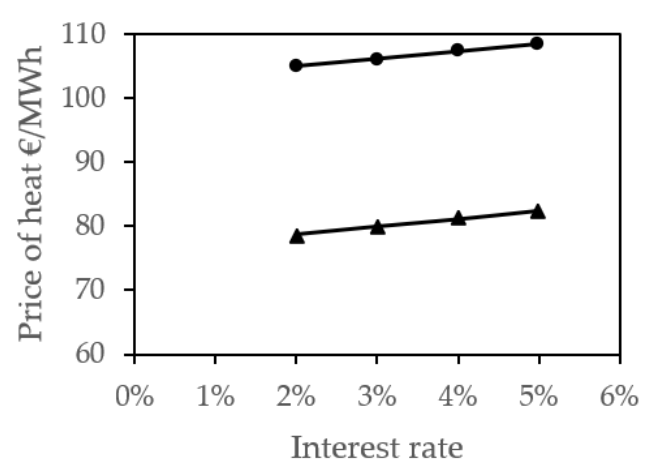

(A)

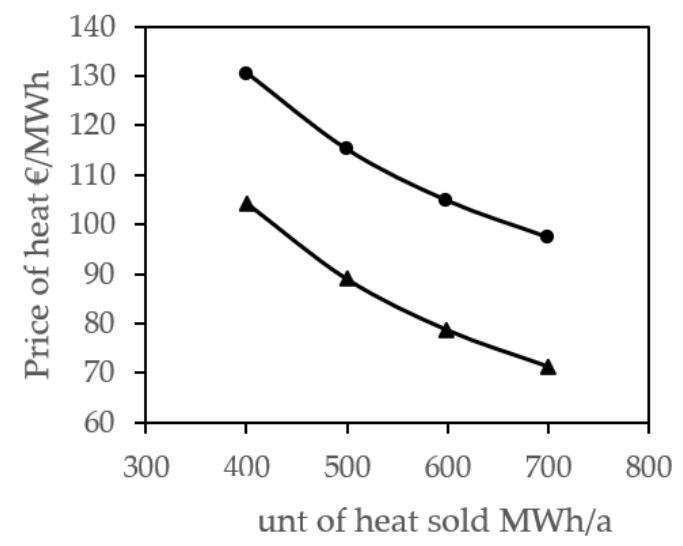

(C)

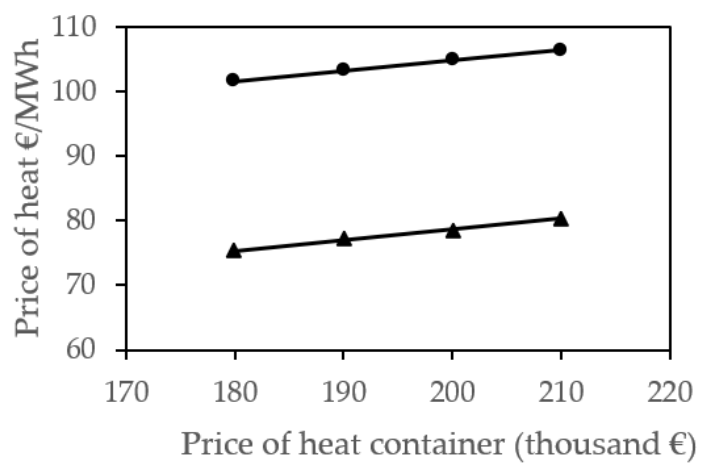

(B)

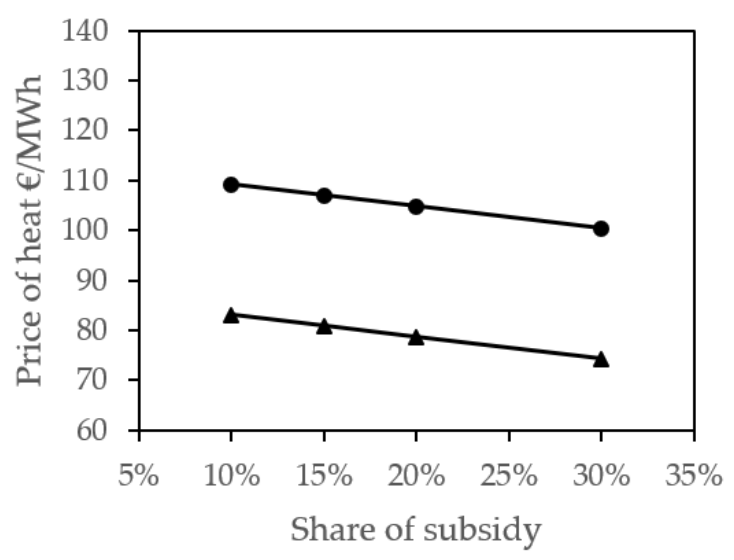

(D)

$\rightarrow$ Paters $\rightarrow$ aipe

Figure 4. Calculation of the minimum price of heat that results in net positive profitability for both pellet and chips based on different variables such as interest rate (A), price of the heat container (B), amount of heat sold in a year (C) and subsidy (D) for heat container sized $300 \mathrm{~kW}$.

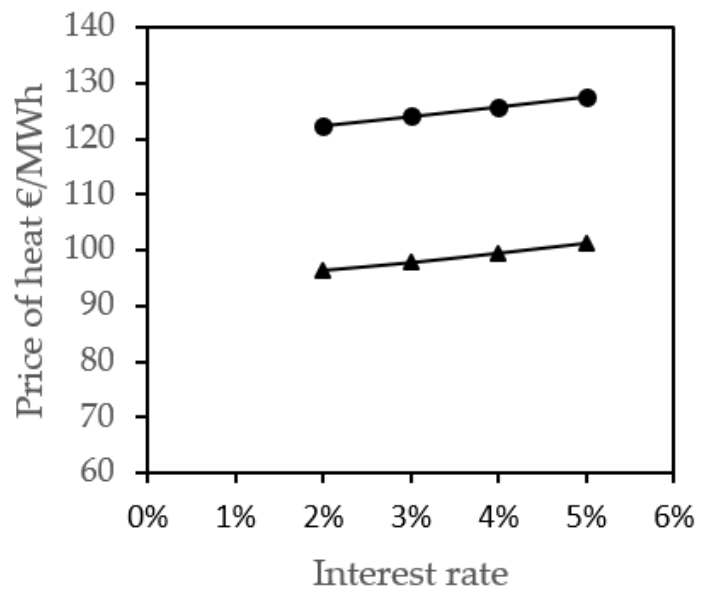

(A)

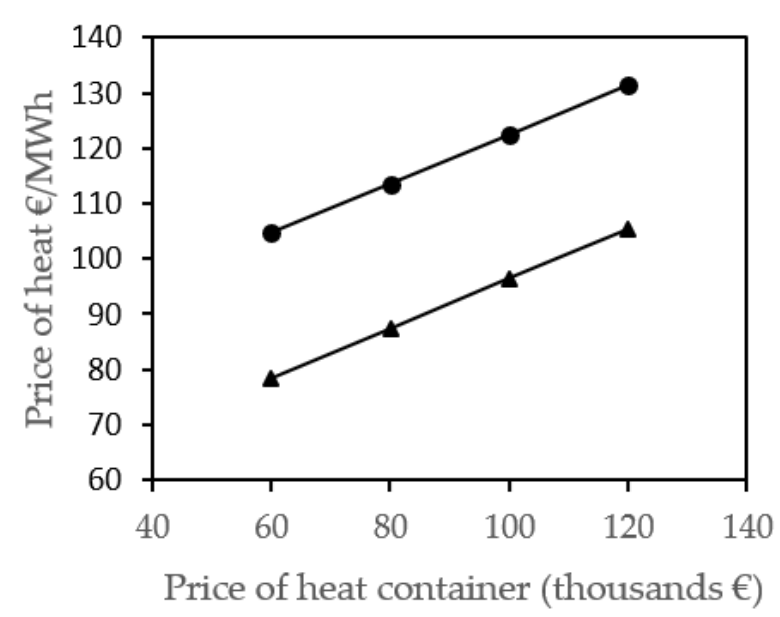

(B)

Figure 5. Cont. 


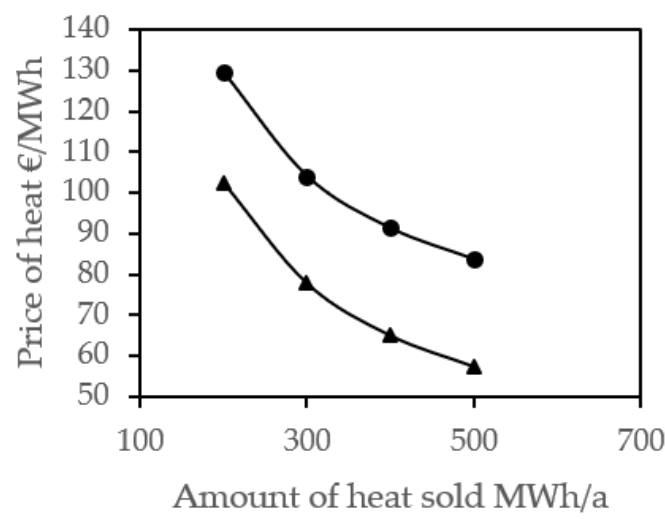

(C)

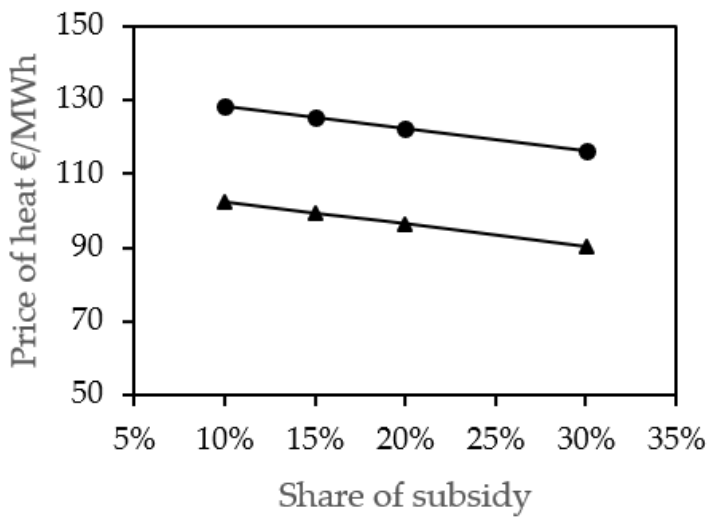

(D)

$\rightarrow$ Pellets $\rightarrow$ Chips

Figure 5. Calculation of minimum price of heat that results in net positive profitability for both pellet and chips based on different variables such as interest rate (A), price of the heat container (B), amount of heat sold in a year (C) and subsidy (D) for heat container sized $110 \mathrm{~kW}$.

Table 2. The price of chips calculated based on the Equation (1). HR: Hirvensalmi roadside, HT: Hirvensalmi terminal, JR: Juva roadside, JT: Juva terminal, SR: Savonlinna roadside, ST: Savonlinna terminal.

\begin{tabular}{ccccccc}
\hline \multirow{2}{*}{ Price of Chips } & \multicolumn{2}{c}{ Hirvensalmi } & \multicolumn{2}{c}{ Juva } & \multicolumn{2}{c}{ Savonlinna } \\
\cline { 2 - 7 } & HR & HT & JR & JT & SR & ST \\
\hline$€ /$ MWh & 18.41 & 20.37 & 18.64 & 20.65 & 19.67 & 22.03 \\
\hline
\end{tabular}

Figure 6 shows that opting for the chips chipped at a terminal would raise the breakeven price of heat by $3 \%$. Similarly, opting for chips from Savonlinna instead of Hirvensalmi (additional $71 \mathrm{~km}$ ) would add $2 \%$ on the break-even price of heat.

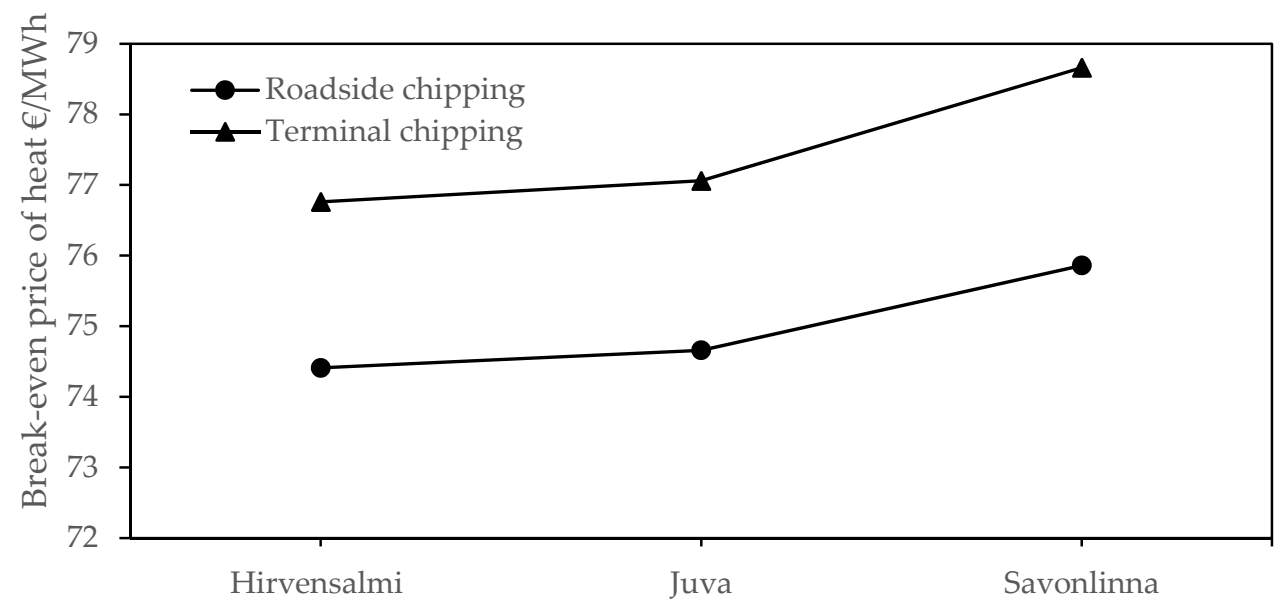

Figure 6. Minimum price of heat for profitability for $300 \mathrm{~kW}$ heat container based on the price of chips originated in different location and chipping method.

\section{Discussions}

According to the Statistics of Finland (Table 3), the district heating (67.41 $€ / \mathrm{MWh})$ still provides cheaper heat than LFO and direct electricity. Despite detached and semidetached dwellings (which are majority in the rural region) occupying 39\% of the total dwellings in Finland [31], only $13 \%$ of the total district heat available is used in those [32]. In contrast, of 
the total LFO-derived heat produced in Finland, $87 \%$ is used in detached and semidetached houses [31,32]. As discussed in this paper, district heating is currently largely inaccessible to the rural communities in Finland due to it being uneconomical because of the heat loss in the network and costly infrastructure for longer heat delivery distances. Thus, the comparison of price of heat derived from direct electricity or LFO is more relevant for rural Finland than comparing with district heat in the context of this study. On the other hand, in $2019,49.5 \%$ of the total district heat produced in Finland was based on fossil fuel (natural gas $10.7 \%$, hard coal $18.1 \%$ ) and peat (14.9\%) [33], thus, changing the heating system from LFO to district heating is not the direction to carbon neutrality in current situation.

Table 3. Consumer prices of heat in Finland in March 2021 [34].

\begin{tabular}{cc}
\hline Energy Type & Prices in $€$ /MWh (Excluding VAT) \\
\hline LFO & 77.34 \\
\hline Household electricity & 114.92 \\
\hline Pellets & 47.42 \\
\hline District heating & 67.41 \\
\hline
\end{tabular}

Figure 7A shows the impact of LFO prices on the price of delivered heat and Figure 7B shows the actual price development of LFO in Finland during April 2018 and May 2021. From these figures, it can be deduced that the price of LFO is fluctuating even in relatively short term and consequently, the price of delivered heat could reach well above 30 EUR/GJ in short period of time. The fluctuating behavior of LFO price and consequent price of heat could drive away dwellings from installing new LFO-derived heating systems.

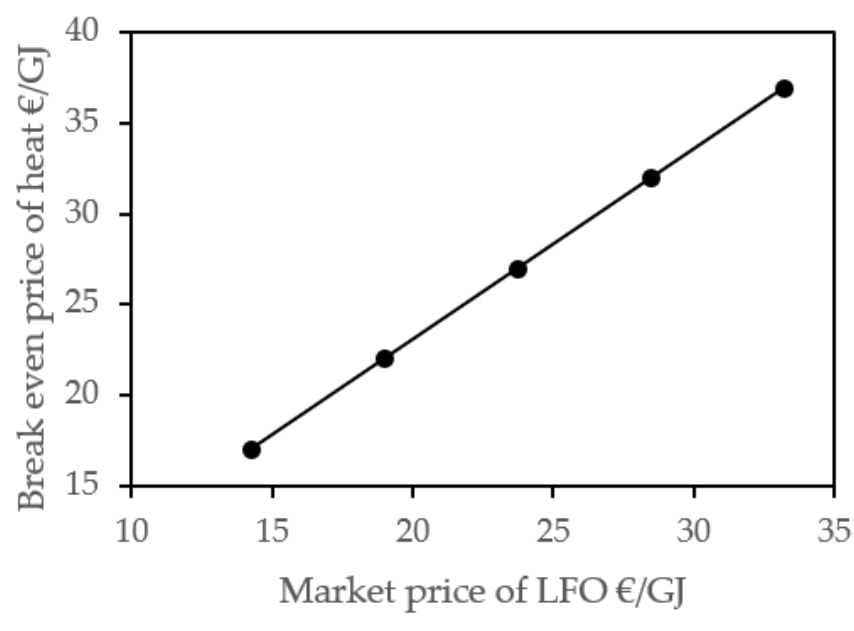

(A)

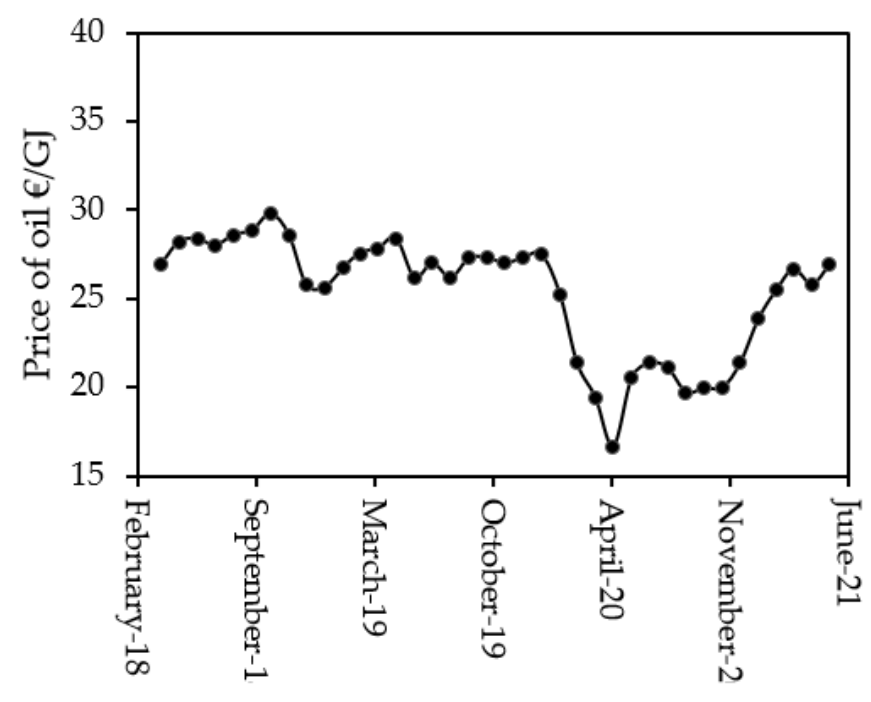

(B)

Figure 7. The break-even price of heat with respect to the price of LFO (calculated) (A), actual consumer price of oil in Finland (VAT excluded) (B) [22].

There is a lack of research specific to heat-containers, but a similar study is done by Hendricks et al. [17], which compared the investment and profitability of small-scale biomass-derived heating in US villages. Their study shows that the price of biomassderived heat ranged from 107.2 USD/MWh to 138.8 USD/MWh from which majority of the studied scenarios are cheaper than the LFO-derived heat (126.8 USD/MWh). In our study, the impact of the interest rate on the delivered heat has comparatively lower $(1.6 \%$ rise in price of heat for every $1 \%$ rise in interest rate) compared to the impact reported by Hendricks et al., who have reported the impact to be $7 \%$ rise in price of heat every $1 \%$ 
raise in the interest rate [17]. On the other hand, impact of wood chips on the price of delivered heat was found to be $5: 1$, that is $5 \%$ increase in price of wood chips raises the price of heat by $1 \%$. Similar results are reported by Hendricks et al., where a $1 \%$ rise in the price of fuel only changes the delivered heat by $0.2 \%$ [17]. One should consider that the scale of the study by Hendricks et al., is larger than in this paper and includes boiler and distribution network.

\subsection{Drivers for the Energy Transition}

In Finland, typical investment support for the installation of renewable energy replacing LFO-derived heating system is $20 \%$, as calculated in this paper. Calculations in this paper showed that raising investment support from $20 \%$ to $30 \%$ would cut the price of heat by $5.6 \%$. Madlener [35] reported that $45 \%$ investment support and capacity expansion kept the economic viability of the biomass derived heating plant in a village in Austria. Finland still has a long way to catch up to such measure. However, Finland introduced a tax deduction mechanism for the labor costs targeted for smaller households which has been popular and such mechanism could be influential for energy transition in the future as well [36]. Ruggiero et al., reports that heavy taxation on fossil fuels and environmental awareness among the people may speed up the energy transition [36]. In Finland, the Center for Economic Development and the Environment (ELY) beginning from June 2020 began to offer a maximum of 4000 EUR to households who would replace oil heating systems with renewable fuel-based heating systems, and by April 19, 2021 ELY has already received 13,125 applications [37]. Lastly, the fluctuating nature of LFO price (as shown in Figure 7B) could also encourage the consumers to renovate their oil heating systems to more stable heating systems and heat entrepreneurs would have an opportunity to capture such market development.

\subsection{Opportunities for the Local Economy}

In addition to being a low-carbon energy source, replacing imported LFO with locally generated forest chips has several advantages for the local economy, including biomass procurement, forest owners, and the transportation sector [38]. In the context of this article heat entrepreneurs, forest owners, biomass terminal and chipper operators, harvesters and other equipment operators, and truck drivers would all be immediate benefactors. According to the input-output analysis by Madlener and Koller, every million invested in a decentralized biomass heating system generates 1.1 million EUR in value-added, including 18 person-years of employment [39]. Madlener and Koller also discovered a significant gross domestic effect in terms of value-added, employment, and fiscal repercussions. Similar positive effects were also predicted by Soltero et al., in their study in rural Spain [40]. In addition to the positive value-added effects on the economy, Lehtonen and Okkonen suggest that there are other socio-economic implications, such as overall household savings (due to lower heating costs) leading to an increase in disposable income, which benefits local product and service providers. However, the authors remain wary of their work because it is a small case study with no long-term socio-economic implications studied extensively [14].

\subsection{Barriers for Investments}

Changing an oil-based heating system to an alternative, according to Hast et al., is not cost-effective for the owners until the heating system reaches the end of its life cycle or the price of oil rises sufficiently [10]. Madlener and Koller also discovered that discouraged investments and premature retirement of existing heating systems would result in displacement effects ranging from $20 \%$ to $40 \%$ of positive value-added effect [39]. The premise in this paper was that heat-containers would be installed at the end-of-life stage of an oil heating system. In practice, however, such conditions are uncommon, and the aggressive energy transition strategy may not be able to wait till the end-of-life stage of 
oil-based heating systems. Significant subsidies may however affect the economics of a heating system renovation.

Young et al., concluded that inadequate financial policies may not necessarily encourage the adoption of biomass because of the high capital costs involved. They also observe that pro-biomass policies frequently target large-scale utilities and manufacturing industries, while small-scale and distributed bioenergy producing facilities are generally overlooked [16] This theory also applies to Finland as Ruggiero et al., report that Finland has adopted very limited policies in the past that in effect promote small-scale distributed energy production [41]. Instead, policymakers' focus has been to secure cheap energy through large, centralized solutions [42]. Nissinen et al. [43] believe that packages of policies are more effective than individual instruments. The authors also believe that such integrated policies need better cooperation among the policy making bodies in the government to improve the effectiveness [43].

According to Ruggiero et al., the lack of infrastructure that allows excess heat to be sold to a broader network discourages heat entrepreneurs [41]. Such an opportunity would likely increase their willingness to invest in heat containers, but then again it is costly to expand heating network to sparsely populated areas.

The situation is similar across the industry as biogas producers are discouraged to produce heat only because of lack of opportunity for selling the excess heat. Biomethane (biogas) is one of the renewable alternatives for the small-scale space heating in Finland, especially for the energy independence of local farms. According to Winquist et al., Finnish biogas production doubled from $52,000 \mathrm{~m}^{3}$ to $110,000 \mathrm{~m}^{3}$ during 2011-2017 but during the same period return on investment degreased halved from $10 \%$ to $5 \%$ for studied biogas plants [44]. Farmers and small-sized energy entrepreneurs are in search for additional revenue streams such as improvised manure production from digestate. Heat and electricity coproduction from biogas is more economically attractive than heat only but the operating cost is still too high, occasionally even higher than market price of the electricity [44]. Thus, the fate of the small-scall energy production in rural region of Finland primarily depends on the focused policy mechanisms and financial subsidies.

\section{Conclusions}

The price of the delivered heat is one of the main determinant factors when it comes to the heating system selection. In this paper, it is established that the heat derived from biomass heat containers is cost competitive with LFO-derived heating system at current price of LFO ( 19 EUR/GJ) even though the initial investment is comparatively higher than oil heaters and storage tank. The figures from the Statistics of Finland (Table 3) show that the average price of delivered heat from oil heating systems was 77.34 EUR/MWh, which is close to the break-even price of heat from biomass chips produced in $300 \mathrm{~kW}$ heat container (78.66 EUR/MWh). The corresponding break-even price of delivered heat from smaller heat containers $(110 \mathrm{~kW})$ is $96.5 \mathrm{EUR} / \mathrm{MWh}$, which suggests that consumers with lower heat need may not find $110 \mathrm{~kW}$ heat container attractive financially. There are ways to lower the break-even price of heat, such as, raising the uptime, lowering the capital costs with the help of state support.

Using wood pellets as a fuel in heat containers is comparatively uneconomical (104.86 EUR/MWh in $300 \mathrm{~kW}$ heat container) because the price of wood pellets is much higher than wood chips and the investment costs are same. The much lower average price of delivered heat from wood pellets in Finland shown in Table 3 is for a small-scale pellets boiler often installed in single detached houses rather than in heat containers which has higher capital costs.

Since rural Finland lacks district heating network, heat containers that generate the cost-competitive heat provide a compelling alternative to LFO-derived heating systems. However, as shown in Figure 7B, the price of LFO fluctuates in short period of time and cheaper price of LFO would mean the residents would find difficult to move away from LFO to renewable source of energy unless stronger intervention from the policymakers. 
Previous studies have suggested that investing in a new heating system and using local forest resource instead of imported LFO has positive socio-economic effects [14,38]. Some studies add that the value-added effect of new investments and the impacts on raw material value-chain is significant for the rural economy $[14,35,38,39]$. In the context of this paper, investment on decentralized heating using local resource could create economic opportunities for small-sized heat entrepreneurs, forest owners and biomass procurement operators. In addition, local citizens could benefit from locally produced cheaper energy which could eventually increases disposable income in the households. However, displacement effect and long-term effect of energy transition on society and the broader economy needs a deeper investigation. In addition, the extent of the lack of focused policy mechanisms and financial incentives for investments on decentralized low-carbon heating systems should also be investigated on a grassroot level.

Author Contributions: Conceptualization, R.K.C.; methodology, R.K.C. and J.F.; writing-original draft preparation, R.K.C.; writing-review and editing, R.K.C., J.F., A.G. and T.R.; supervision, T.R. All authors have read and agreed to the published version of the manuscript.

Funding: This research was a part of the project "Innovative Solution for Solid Biomass Delivery and Mobile Heat Containers to Replace Oil-fired Heating". The project was primarily funded by the Regional Council of South Savo from the European Regional Development Fund (Project code: A74618). The project also received funding from the Suur-Savon Energiasäätiö.

Conflicts of Interest: The authors declare no conflict of interest.

\section{References}

1. IPCC. Global Warming of $1.5^{\circ} \mathrm{C}$. An IPCC Special Report on the Impacts of Global Warming of $1.5^{\circ} \mathrm{C}$ above Pre-Industrial Levels and Related Global Greenhouse Gas Emission Pathways, in the Context of Strengthening the Global Response to the Threat of Climate Change, Sustainable Development, and Efforts to Eradicate Poverty; Masson-Delmotte, V., Zhai, P., Pörtner, H.-O., Roberts, D., Skea, J., Shukla, P.R., Pirani, A., Moufouma-Okia, W., Péan, C., Pidcock, R., et al., Eds.; IPCC: Geneva, Switzerland, 2018.

2. Carbon Neutral Finland. 2021. Objective 1: Finland Will Achieve Carbon Neutrality by 2035. Available online: https:// valtioneuvosto.fi/en/marin/government-programme/strategic-themes (accessed on 19 April 2021).

3. Cross, S.; Welfle, A.J.; Thornley, P.; Syri, S.; Mikaelsson, M. Bioenergy development in the UK \& Nordic countries: A comparison of effectiveness of support policies for sustainable development of the bioenergy sector. Biomass Bioenergy 2021, $144,105887$.

4. Statistics of Finland. Total Energy Consumption by Energy Source (All Categories), 1970-2020. Available online: https://pxnet2 .stat.fi/PXWeb/pxweb/en/StatFin/StatFin_ene_ehk/statfin_ehk_pxt_12vq.px/ (accessed on 20 August 2021).

5. Statistics of Finland. Final Energy Consumption by Sector, 1970-2020*. Available online: https://pxnet2.stat.fi/PXWeb/pxweb/ en/StatFin/StatFin_ene_ehk/statfin_ehk_pxt_12vk.px/ (accessed on 20 August 2021).

6. $\quad$ Lindroos, T.J.; Mäki, E.; Koponen, K.; Hannula, I.; Kiviluoma, J.; Raitila, J. Replacing fossil fuels with bioenergy in district heating-Comparison of technology options. Energy 2021, 231, 120799. [CrossRef]

7. Rikkonen, P.; Tapio, P.; Rintamäki, H. Visions for small-scale renewable energy production on Finnish farms-A Delphi study on the opportunities for new business. Energy Policy 2019, 129, 939-948. [CrossRef]

8. Statistics of Finland. Heating System. 2021. Available online: https://www.stat.fi/meta/kas/lam_tapa_en.html (accessed on 11 August 2021).

9. Official Statistics of Finland (OSF): Energy Consumption in Households. ISSN=2323-329X. 2019, Appendix Table 2. Energy Consumption in Households by Energy Source in 2019, GWh. Helsinki: Statistics Finland. Available online: http://www.stat.fi/ til/asen/2019/asen_2019_2020-11-19_tau_002_en.html (accessed on 11 August 2021).

10. Hast, A.; Ekholm, T.; Syri, S. What is needed to phase out residential oil heating in Finnish single-family houses? Sustain. Cities Soc. 2016, 22, 49-62. [CrossRef]

11. DIN EN 303-5. European Standard. Available online: https://www.en-standard.eu/din-en-303-5-heating-boilers-part5-heating-boilers-for-solid-fuels-manually-and-automatically-stoked-nominal-heat-output-of-up-to-500-kw-terminologyrequirements-testing-and-marking/ (accessed on 11 August 2021).

12. Biofire. Hakelämpö-Kontti Integroidulla Varastolla-Teholuokat 60-500 kW. 2021. Available online: https://www.biofire.fi/ hakelampokontti/ (accessed on 1 June 2020).

13. Föhr, J.; KC, R.; Ranta, T.; Miettinen, M. Hydraulically Powered Wood Chip Blower in Test and Its Use Opportunity in Biofuel Supply Chain. J. Sustain. Bioenergy Syst. 2020, 10, 77-91. [CrossRef]

14. Lehtonen, O.; Okkonen, L. Energy cost reduction creates additional socioeconomic benefits-The case of Eno Energy Cooperative, Finland. Energy Policy 2019, 129, 352-359. [CrossRef]

15. Anca-Couce, A.; Hochenauer, C.; Scharler, R. Bioenergy technologies, uses, market and future trends with Austria as a case study. Renew. Sustain. Energy Rev. 2021, 135, 110237. [CrossRef] 
16. Young, J.D.; Anderson, N.M.; Naughton, H.T. Influence of policy, air quality, and local attitudes toward renewable energy on the adoption of woody biomass heating systems. Energies 2018, 11, 2873. [CrossRef]

17. Hendricks, A.M.; Wagner, J.E.; Volk, T.A.; Newman, D.H.; Brown, T.R. A cost-effective evaluation of biomass district heating in rural communities. Appl. Energy 2016, 162, 561-569. [CrossRef]

18. Hess, D.J.; Sovacool, B.K. Sociotechnical matters: Reviewing and integrating science and technology studies with energy social science. Energy Res. Soc. Sci. 2020, 65, 101462. [CrossRef]

19. Peltola, T. Energy Policy or Forest Policy or Rural Policy? Transition from Fossil to Bioenergy in Finnish Local Heating Systems. In Energy, Policy, and the Environment. Studies in Human Ecology and Adaptation; Järvelä, M., Juhola, S., Eds.; Springer: New York, NY, USA, 2011; Volume 6, pp. 155-171.

20. Komendantova, N. Transferring awareness into action: A meta-analysis of the behavioral drivers of energy transitions in Germany, Austria, Finland, Morocco, Jordan and Iran. Energy Res. Soc. Sci. 2021, 71, 101826. [CrossRef]

21. Official Statistics of Finland (OSF): Producer Price Indices. ISSN=1799-3695. February 2021, Appendix Table 25. Wood Pellet, Consumer Price. Helsinki: Statistics Finland. Available online: http://www.stat.fi/til/thi/2021/02/thi_2021_02_2021-03-24 _tau_025_en.html (accessed on 10 August 2021).

22. Official Statistics of Finland. Consumer Price of Liquid Fuel (VAT Included). 2021. Statistics Finland's Free-of-Charge Statistical Databases. Helsinki. Available online: https://pxnet2.stat.fi/PXWeb/pxweb/en/StatFin/StatFin_ene_ehi/statfin_ehi_pxt_ 12ge.px/ (accessed on 23 June 2021).

23. Engineering ToolBox, Fuels-Higher and Lower Calorific Values. Available online: https://www.engineeringtoolbox.com/fuelshigher-calorific-values-d_169.html (accessed on 9 September 2021).

24. Miettinen, M.; Lämpösi Oy, Jyväskylä, Finland. Personal communication, 2021.

25. Alakangas, E.; Hurskainen, M.; Laatikainen-Luntama, J.; Korhonen, J. Suomessa Käytettävien Polttoaineiden Ominaisuuksia; VTT TECHNOLOGY 258; VTT Technical Research Centre of Finland: Espoo, Finland, 2000; ISBN 9789513884192.

26. LUKE. Volumes and Prices in Industrial Roundwood Trade. 2021. Available online: https://stat.luke.fi/en/volumes-and-pricesroundwood-trade (accessed on 21 June 2021).

27. Karttunen, K.; Laitila, J. Forest management regime options for integrated small-diameter wood harvesting and supply chain from young Scots pine (Pinus sylvestris L.) stands. Int. J. For. Eng. 2015, 26, 124-138.

28. Laitila, J.; Väätäinen, K. Truck transportation and chipping productivity of whole trees and delimbed energy wood in Finland. Croat. J. For. Eng. 2012, 33, 199-210.

29. Obernberger, I.; Thek, G. The Pellet Handbook: The Production and Thermal Utilisation of Pellets; Routledge: Abingdon, UK, 2010; p. 241.

30. Jormakka, R.; Koivusalo, K.; Lappalainen, J.; Niskanen, M. Laskentatoimi [Accounting]; Edita: Helsinki, Finand, 2009 ; p. 234. ISBN 9789513764784.

31. Official Statistics of Finland (OSF): Dwellings and Housing Conditions. ISSN=1798-6761. Overview 2019, 2. Household-Dwelling Units and Housing Conditions 2019. Helsinki: Statistics Finland. Available online: http://www.stat.fi/til/asas/2019/01/asas_20 19_01_2020-10-14_kat_002_en.html (accessed on 8 October 2021).

32. Official Statistics of Finland (OSF): Energy Consumption in Households. ISSN=2323-329X. Helsinki: Statistics Finland. Available online: https://pxnet2.stat.fi/PXWeb/pxweb/en/StatFin/StatFin_ene_asen/statfin_asen_pxt_11zr.px/table/ tableViewLayout1/ (accessed on 11 October 2021).

33. Official Statistics of Finland (OSF): Production of Electricity and Heat. ISSN=1798-5099. Helsinki: Statistics Finland. Available online: https:/ / pxnet2.stat.fi/PXWeb/pxweb/en/StatFin/StatFin_ene_salatuo/statfin_salatuo_pxt_12b7.px/ (accessed on 8 October 2021).

34. Statistics: Energy Prices. ISSN=1799-800X. 1st Quarter 2021, Appendix Table 3. Consumer Prices of Heating Energy in March 2021. Helsinki: Statistics Finland. Available online: http://www.stat.fi/til/ehi/2021/01/ehi_2021_01_2021-06-10_tau_003_en.html (accessed on 12 August 2021).

35. Madlener, R. Innovation diffusion, public policy, and local initiative: The case of wood-fuelled district heating systems in Austria. Energy Policy 2007, 35, 1992-2008. [CrossRef]

36. Ruggiero, S.; Varho, V.; Rikkonen, P. Transition to distributed energy generation in Finland: Prospects and barriers. Energy Policy 2015, 86, 433-443. [CrossRef]

37. ELY 2021. To Those Who Want to Change Oil Heating System. Available online: https://www.ely-keskus.fi/oljylammityksenvaihtajalle (accessed on 21 April 2021).

38. Hendricks, A.M.; Wagner, J.E.; Volk, T.A.; Newman, D.H. Regional economic impacts of biomass district heating in rural New York. Biomass Bioenergy 2016, 88, 1-9. [CrossRef]

39. Madlener, R.; Koller, M. Economic and $\mathrm{CO}_{2}$ mitigation impacts of promoting biomass heating systems: An input-output study for Vorarlberg, Austria. Energy Policy 2007, 35, 6021-6035. [CrossRef]

40. Soltero, V.M.; Chacartegui, R.; Ortiz, C.; Velázquez, R. Potential of biomass district heating systems in rural areas. Energy 2018, 156, 132-143. [CrossRef]

41. Ruggiero, S.; Martiskainen, M.; Onkila, T. Understanding the scaling-up of community energy niches through strategic niche management theory: Insights from Finland. J. Clean. Prod. 2018, 170, 581-590. [CrossRef]

42. Huttunen, S. Stakeholder frames in the making of forest bioenergy legislation in Finland. Geoforum 2014, 53, 63-73. [CrossRef] 
43. Nissinen, A.; Heiskanen, E.; Perrels, A.; Berghäll, E.; Liesimaa, V.; Mattinen, M. Combinations of policy instruments to decrease the climate impacts of housing, passenger transport and food in Finland. J. Clean. Prod. 2014, 107, 455-466. [CrossRef]

44. Winquist, E.; Rikkonen, P.; Pyysiäinen, J.; Varho, V. Is biogas an energy or a sustainability product?-Business opportunities in the Finnish biogas branch. J. Clean. Prod. 2019, 233, 1344-1354. [CrossRef] 